\title{
Effect of Self Esteem Enhancement on Assertiveness of School Students
}

\author{
Ms. Urvashi Shrivastava ${ }^{1 *}$, Dr. Vinay Mishra ${ }^{2}$
}

\section{ABSTRACT}

Self-esteem is one of the core aspects of human life, upon which we shape our behavior and attitude. It is primarily our evaluation about our own self. Assertiveness is the quality of an individual to be self-assured and confident without being aggressive. The present study employed an experimental pre test post test method and aims at assessing the effect of SE enhancement on assertiveness of school students of Bhopal. Coopersmith Self Esteem Scale and Assertiveness Inventory were used as tools. It was concluded that SE enhancement had a positive significant effect on the assertiveness of school children. Also, the mean assertiveness score for boys and girls did not show any significant difference.

Keywords: Self Esteem Enhancement, Assertiveness, Adolescents.

Self-esteem (SE) is the evaluation of the self made by an individual (Coopersmith, 1967) and one's attitude towards oneself along a positive-negative dimension. It reflects an individual's implicit judgment of his own ability to cope with the challenges of his life and of his right to be happy. A person experiencing high SE believes himself to be fundamentally good, capable, and worthy of love and affection. Low SE is a view of oneself as useless, inept and unworthy of love and respect from others.

Feeling of inferiority and lack of self-confidence are typical of a low SE individual. Such feelings are manifested in two ways. The individual may altogether shrink from many tasks that require his attention with strong feelings that he is not good enough to perform adequately or he may actively try to overcome such feelings by appearing boastful or overconfident of his abilities. The well-adjusted person, on the other hand, does not deprecate himself but feels adequate and equal to others in facing most of the situations that arise in day-to-day living.

Opinions expressed by others help shape one's self evaluation and outsider's opinions bring about changes in one's self esteem. Any experience that creates a positive mood tends to raise $\mathrm{SE}$. To grow in SE is to grow in the conviction that one is competent enough to lead a successful life and is worthy of happiness, and therefore, to be able to face life with greater confidence,

\footnotetext{
${ }^{1}$ Department of Psychology, Bhopal School of Social Sciences, Bhopal, India

${ }^{2}$ Department of Psychology, Bhopal School of Social Sciences, Bhopal, India *Corresponding Author

(C) 2015 I U Shrivastava, V Mishra; licensee IJIP. This is an Open Access Research distributed under the terms of the Creative Commons Attribution License (http://creativecommons.org/licenses/by/2.0), which permits unrestricted use, distribution, and reproduction in any Medium, provided the original work is properly cited.
} 


\section{Effect of Self Esteem Enhancement on Assertiveness of School Students}

benevolence, and optimism, which helps one to reach goals and experience fulfillment. The better the SE, the more likely is an individual to be ambitious, not necessarily just in career, but in terms of what one hopes to achieve in life emotionally, creatively, and spiritually also.

Assertiveness refers to the ability of an individual to stand up for his self and yet not harm the respect/status of the other person. It helps to set proper boundaries for oneself and stick to them. An assertive person has the confidence to say 'no' to a request made to him when he feels he may not be up to performing that act without hurting the person making the request and without feeling guilty about saying 'no'.

They realize that they are responsible for their own choices, but not for others' choices; that they can negotiate with others for the changes they wish to make; and that it is okay to be powerful and self-validating. Assertiveness is also accompanied with the ability to communicate openly and honestly and that expressing oneself is as important as listening to others.

When an individual starts to accept himself, forms a strong sense of identity and become selfaware, i.e. has a high positive SE, he starts to feel better about himself and he starts to treat himself with respect. He also starts to expect the same degree of respect from others and accords them with the same.

The similarities evident in the nature of assertiveness and high SE suggest a positive correlation between SE and assertiveness. Karagözoğlu et al. (2008) concluded that nursing students who had the highest SE also had the highest levels of assertiveness. The power component of differentiated SE was found to have a high correlation with global SE and with assertiveness than with other components (Johnson, 1993) and has established a positive correlation between SE and assertiveness.

Assertiveness training refers to enhancing levels of assertiveness in individuals through various cognition-based activities. Shimizu et al. (2004) demonstrated that the SE of Japanese nurses could be raised through assertiveness training. Assertiveness training increases interpersonal competence, self-confidence, SE and perceived self-control and that it decreases fear and anxiety (Bower and Bower, 1976, Lange and Jakubowski, 1976, Lefevre and West, 1981, Delamater and McNamara, 1986, Williams and Stout, 1984).

Temple and Robson (1991) record high significant improvements in SE at the completion of as well as at follow-up following an assertiveness training course. Brown and Carmichael (1992) found statistically significant increase in participants' level of assertiveness and SE in subjects with psychiatric illness. SE and assertiveness were significantly inversely related to stress, with assertiveness contributing to SE and SE being directly related to stress in fire-fighters (Petrie and Rotheram, 1982). Assertiveness and SE was found to improve significantly after assertiveness 
training (Lin et al., 2004). Enns (1992) has discussed the effect of assertiveness on SE through her research on SE enhancement groups.

Having a high SE and being assertive are key components of an individual's personality. They are essential for an individual to lead a satisfied life, have healthy relationships and live a happy life. Only when an individual feels good about his self, will he be assertive too. The nature of the relationship between SE and assertiveness has been established through various researches; the effect of assertiveness training on SE has also been well documented. However, the effect of SE enhancement on assertiveness has not been well studied. Hence, the present study was taken up to study the effect of SE enhancement on assertiveness of adolescents. Stake, DeVille and Pennell (1983) have specified that low SE subjects showed higher increases as compared to high SE subjects, hence low SE adolescents were screened out for the study to administer the SE enhancement program and assess the effect of the program on assertiveness.

\section{Hypotheses}

1. The post-test mean assertiveness of the experimental group (for boys and girls together, for boys only and for girls only) will be significantly higher than that of the pre-test cond ition.

2. The pre-test and post-test assertiveness means of the control group will not show any sig nificant difference.

3. The post-test mean assertiveness score of the experimental group will be significantly hi gher than that of the control group.

4. There will be no significant difference between mean assertiveness scores for boys and g irls group (post-test only).

\section{Sample}

The sample for the present study was selected from coeducational schools of Bhopal. The initial sample consisted of 658 students of 8th and 9th class - 416 boys and 242 girls. Students who had low levels of SE were screened out with the help of Coopersmith Self Esteem Inventory. The final sample, thus, consisted of 155 students with low SE out of which 91 were boys and 64 were girls.

\section{Tools}

\section{Coopersmith Self Esteem Inventory (CSEI)}

The inventory has been constructed by Dr. S. Coopersmith (1981). It intends to measure the SE of individuals in four areas: social, academic, family and personal. The inventory is available in three forms: the school form, the school short form and the adult form. For the present study, the school form was used. The school form is applicable to students between 8 to 15 years. The reliability of the school form has been well documented. Kimball (1972) calculated the reliability of the school form for grades 4 to 8, it's coefficients ranged from 0.87 to 0.92 for various grades. Kimball (1972) and Kokenes $(1974,78)$ confirmed the construct validity of the subscales as 
measuring sources of SE. Simon and Simon (1975) correlated the CSEI school form with SRA Achievement Series. It's coefficient is reported as 0.33 ( $p<0.01)$.

\section{Assertiveness Inventory (AI)}

Assertiveness Inventory has been constructed and standardized by Dr. Tasneem Naqvi. The test intends to measure assertiveness in two areas: assertive behavior and blocks occurring in behaving assertively. For the present study, only assertive behavior was assessed. Reliability of AI by split-half method as calculated by Spearman-Brown formula is 0.821 for part I. Validity has been computed by point-biserial correlation method by using Garrett's (1967) formula, which indicates that the test is a valid measure of assertiveness.

\section{Self Esteem Enhancement Package (SEEP)}

The SEEP comprises of 20 sessions which aimed at generating self-awareness, developing realistic self-concept and enhancing self-worth of adolescents. Audio- visual aids, affirmations, talent hunt, goal-setting, group as well as individual exercises were some of the activities included in the package.

\section{Procedure}

The design of the present study was experimental pre-test post-test design with an experimental and a control group. At the start, an orientation was conducted for the students. Next, pre-testing of SE was conducted to screen out students with low SE. These screened out students were then administered the AI. The students who were screened out were divided into two groups: experimental group and control group. The experimental group was imparted the SEEP, whereas the control group was given no intervention. After the completion of the enhancement package with the experimental group, both the groups were again tested on the AI to assess the change in assertiveness levels.

\section{RESULTS}

For the verification of the hypotheses set earlier, ' $t$ ' test was applied to assess the significance of difference between the mean assertiveness scores. The first hypothesis was tested in three parts: a) for the combined group, b) for boys group, and c) for girls group. The mean assertiveness score for the combined group was found to be 60.75 and 65.45 for pre-test and post-test conditions respectively. The obtained data is indicated in table 1.

Table 1. Mean assertiveness scores, $S D, S E_{D}$ and ' $\mathrm{z}$ ' value for pre- and post-test conditions of experimental group (Combined group)

\begin{tabular}{|l|l|l|l|l|l|}
\hline Condition & $\mathbf{N}$ & $\mathbf{M}$ & $\mathbf{S D}$ & $\mathbf{S E}_{\mathbf{D}}$ & $\mathbf{Z}$ \\
\hline Pre-test & 125 & 60.75 & 14.98 & 1.11 & $4.23 * *$ \\
\hline Post-test & 125 & 65.45 & 15.17 & & \\
\hline
\end{tabular}


While verifying the second part of the first hypothesis, mean assertiveness scores for the boys group was found to be 62.62 for pre-test and 67.10 for post-test condition. The obtained data is indicated in table 2.

Table 2. Mean assertiveness scores, $S D, S E_{D}$ and ' $\mathrm{z}$ ' value for pre- and post-test conditions of experimental group (Boys group)

\begin{tabular}{|l|l|l|l|l|l|}
\hline Condition & $\mathbf{N}$ & $\mathbf{M}$ & $\mathbf{S D}$ & $\mathbf{S E}_{\mathbf{D}}$ & $\mathbf{Z}$ \\
\hline Pre-test & 69 & 62.62 & 15.01 & 1.44 & $3.11^{* *}$ \\
\hline Post-test & 69 & 67.10 & 14.29 & & \\
\hline
\end{tabular}

While verifying the third part of the hypothesis, mean assertiveness scores for the girls group were found to be 58.45 and 63.41 for pre-test and post-test conditions respectively. The obtained data is depicted in table 3.

Table 3. Mean assertiveness scores, $S D, S E_{D}$ and ' $\mathrm{z}$ ' value for pre- and post-test conditions of experimental group (Girls group)

\begin{tabular}{|l|l|l|l|l|l|}
\hline Condition & $\mathbf{N}$ & $\mathbf{M}$ & $\mathbf{S D}$ & $\mathbf{S E}_{\mathbf{D}}$ & $\mathbf{Z}$ \\
\hline Pre-test & 56 & 58.45 & 14.61 & 1.74 & $2.85^{* *}$ \\
\cline { 1 - 3 } Post-test & 56 & 63.41 & 15.94 & & \\
\hline
\end{tabular}

Comparing the pre- and post-test means of the three groups (boys and girls group combined, boys group and girls group), it is evident that the post-test mean scores are higher than the pretest mean scores. Also, the ' $t$ ' values have been found significant, the first hypothesis set stands not rejected indicating that there is a significant positive effect of SE enhancement on assertiveness of adolescents with low SE.

While testing the second hypothesis, the pre-test mean assertiveness score for the control group was found to be 62.2 and the post-test mean was 59.0. The obtained data is indicated in table 4.

Table 4. Mean assertiveness scores, $S D, S E_{D}$ and ' $\mathrm{z}$ ' value for pre- and post-test conditions of control group

\begin{tabular}{|l|l|l|l|l|l|}
\hline Condition & $\mathbf{N}$ & $\mathbf{M}$ & $\mathbf{S D}$ & $\mathbf{S E}_{\mathbf{D}}$ & $\mathbf{Z}$ \\
\hline Pre-test & 30 & 62.2 & 10.85 & 2.28 & 1.40 \\
\hline Post-test & 30 & 59.0 & 12.92 & & \\
\hline
\end{tabular}

On the basis of the above data, it can be concluded that the second hypothesis stands not rejected indicating that there is no significant difference in the pre-test and post-test mean assertiveness scores for the control group.

Next, the mean difference in the post-test assertiveness scores of the experimental and control group was studied to test the third hypothesis. The post-test mean assertiveness score of the experimental group was found to be 63.45 and that of the control group was 59.0. The data obtained is depicted in table 5. 
Table 5. Mean assertiveness scores, $S D, S E_{D}$ and ' $\mathrm{z}$ ' value for experimental and control group (post-test only)

\begin{tabular}{|l|l|l|l|l|l|}
\hline Condition & $\mathbf{N}$ & $\mathbf{M}$ & $\mathbf{S D}$ & $\mathbf{S E}_{\mathbf{D}}$ & $\mathbf{Z}$ \\
\hline $\begin{array}{l}\text { Experimental } \\
\text { group }\end{array}$ & 125 & 63.45 & 15.17 & 2.72 & $2.37^{* *}$ \\
\cline { 1 - 4 } Control group & 30 & 59.0 & 12.92 & & \\
\hline
\end{tabular}

The third hypothesis stands not rejected in light of the above data indicating that there is a significant difference in the post-test mean assertiveness scores of the experimental and control group.

In testing the fourth hypothesis, the post-test mean assertiveness score for boys group (of the experimental group) was found to be 67.10 and for the girls group was found to be 63.41 . The obtained data is shown in table 6 .

Table 6. Mean assertiveness scores, $S D, S E_{D}$ and ' $\mathrm{z}$ ' value for boys and girls of the experimental group (post-test only)

\begin{tabular}{|l|l|l|l|l|l|}
\hline Condition & $\mathbf{N}$ & $\mathbf{M}$ & $\mathbf{S D}$ & $\mathbf{S E}_{\mathbf{D}}$ & $\mathbf{Z}$ \\
\cline { 1 - 5 } & 69 & 67.10 & 14.29 & 2.74 & 1.35 \\
\cline { 1 - 4 } Girls & 56 & 63.41 & 15.94 & & \\
\hline
\end{tabular}

It can be concluded that the fourth hypothesis stands not rejected, indicating that there is no significant difference in the post-test mean assertiveness scores for the boys and girls group of the experimental group.

\section{DISCUSSION}

The present study aims at finding out the effect of SE enhancement on assertiveness levels. An experimental pre test post test method was employed for the study. It was decided to check the efficacy of the enhancement package on adolescents with low self esteem as low self esteem is associated with many internalized and externalized behaviors which are mainly maladaptive.

Going through the data obtained, it can be concluded that there is a significant increase in the assertiveness scores of the experimental group as a function of the SEEP. This increase can be seen in the experimental group as a whole as well as in the boys group and the girls group separately. The fact that the assertiveness levels of the control group do not show significant increase also lends support to the fact that the increase in the mean assertiveness scores of the experimental group was a result of the SEEP. The post-test mean assertiveness scores of the experimental and control group were further compared to support the above findings and the post-test mean assertiveness score of the experimental group was found to be significantly higher than that of the control group. This lends to the evidence that there has been a significant positive effect of the self esteem enhancement package on the assertiveness of adolescents. 
SE refers to the value an individual assigns to his self, how he perceives himself and the worth he places on his self as regards his position in the world. Having a healthy SE ensures that an individual surrounds himself with healthy, worth-while as well as meaningful relationships. It also helps to determine how well an individual treats his self and how he expects others to treat him. When an individual has high SE, he is able to face various situations as well as people with élan. He is also able to stand strong for his opinions and is able to take a step back to other more deserving individuals without feeling inferior to or threatened by them. Assertiveness refers to the ability to stand up for oneself while respecting other's viewpoint. Having a high self esteem would ensure assertiveness also in an individual as is indicated by the results of the present study. Healthy self esteem has been associated with higher satisfaction with life and fulfillment spiritually, professionally as well as emotionally. An individual can voice his opinions only when he is secure in his self.

Furthermore, it can be seen that even though the mean assertiveness score (post-test) of the boys is higher than that of girls, this difference is not statistically significant. Even in a traditional society like India, where in spite of the advancement of technology, the values remain same. But with the changing trends of the society, members of both the genders are being given equal opportunities for education and occupation and are being accorded a position that is at par with the opposite gender. Everyone today is being motivated to express his opinion, though without hurting the sentiments of others still remains important. At present, the society in general has become more assertive towards their rights than what it was earlier and may account for no gender difference in the assertiveness of the present sample.

\section{CONCLUSION}

Enhancing self esteem has had a significant positive effect on the assertiveness of adolescents. Also, no gender difference could be observed in the increase in assertiveness. The delimitation of the study is that only subjects with low SE were retained in the study. The effect of SE enhancement on assertiveness of average and high SE subject was not assessed. The intervention module consisted of 20 sessions only. For optimum benefits, the intervention module could have been longer. Parents and teachers were not involved in the present study which can be included in a longer intervention module. Also, a follow-up was not conducted to assess as to how long the effect of SE enhancement package persisted on the assertiveness levels of the subjects. Students of $8^{\text {th }}$ and $9^{\text {th }}$ class were taken as a part of the sample for the study, who are at an impressionable age and may respond better to the personal attention being given by the researchers. Whether similar results would be visible in elder subjects would be a possible avenue to be researched.

\section{REFERENCES}

Bower, S.A. and Bower, G.H. (1976). Asserting yourself: A practical guide for positive change. Addison-Wesley: Reading, Mass. 
Brown, T.G. and Carmichael, K. (1992). Assertiveness training for clients with a psychiatric illn ess: a pilot study. The British Journal of Occupational Therapy, 55(4), 137-140.

Coopersmith, S. (1967). The antecedents of self esteem. San Francisco, CA: Freeman.

Delamater, R.J. and McNamara, J.R. (1986). The social impact of assertiveness - research findin gs and clinical implications. Behavior Modification, 10, 139-158.

Enns, C.Z. (1992). Self-esteem groups: a synthesis of consciousness-raising and assertiveness-tra ining. Journal of Counseling and Development, 71 (1), 7-13.

Johnson, L. (1993). Nurses in OR are more Assertive than Radiographers. Aust JAdv Nurs., 10 (3 ), 20-26.

Karagözoğlu, S., Kahve, E., Kos, O. and Adamişoğlu, D. (2008). Self-esteem and assertiveness i n final year turkish university students. Nurse Educ Today, 28 (5), 641-649.

Kimball, O.M. (1972). Development of norms for the Coopersmith self esteem inventory: Grades four through eight. Northern Illinois University. Dissertation Abstracts International, 34, 1131-1132.

Lange, A.J. and Jakubowski, P. (1976). Responsible assertive behavior: Cognitive/behavioral pr ocedures for trainers. Research Press: Champaign, Ill.

Lefevre, E.R. and West, M.L. (1981). Assertiveness: Correlations with SE, locus of control, inter personal anxiety, fear of disapproval, and depression. Psychiatric Journal of the Universit y of Ottawa, 6(4), 247-251.

Lin, Y.R., Shiah, I.S., Chang, Y.C., Lai, T.J., Wang, K.Y. and Chou, K.R. (2004). Evaluation of as assertiveness training program on nursing and medical students' assertiveness, self este em and interpersonal communication satisfaction. Nurse Educ Today, 24 (8), 656-665.

Petrie, K. and Rotheram, M.J. (1982). Insulators against stress: self esteem and assertiveness. Psy chological Reports, 50, 963-966.

Shimizu, T., Kubota, S., Mishima, N. and Nagata, S. (2004). Relationship between self esteem a nd assertiveness training among Japanese hospital nurses. Journal of Occupational Healt $h, 46,296-298$.

Simon, W.E. and Simon, W.G. (1975). Self esteem, intelligence, and standardized academic achi evement. Psychology in the Schools, 12, 97-100.

Temple, S. and Robson, P. (1991). Effect of assertiveness training and self esteem. The British J ournal of Occupational Therapy, 54(9), 329-332.

Williams, J.M. and Stout, J.K. (1984). The effect of high and low assertiveness on locus of contr ol and health problems. J. Psychol., 119, 169-173. 